\title{
Morphological Analysis of Blind-Side Hypermelanosis of the Starry Flounder, Platichthys stellatus during Early Development
}

\author{
${ }^{\dagger}$ Duk-Young Kang ${ }^{1}$, Soon-Gyu Byun ${ }^{2}$, Jeong-In Myeong ${ }^{3}$, Hyo-Chan Kim ${ }^{1}$ and Byoung-Hwa Min ${ }^{3}$ \\ ${ }^{1}$ West Sea Fisheries Research Institute, NFRDI, Incheon 400-420, Republic of Korea \\ ${ }^{2}$ Southeast Sea Fisheries Research Institute, NFRDI, Namhae 668-821, Republic of Korea \\ ${ }^{3}$ National Fisheries Reasearch Development and Institute, Busan 619-705, Republic of Korea
}

\begin{abstract}
In Pleuronectiformes, blind-side malpigmentation (hypermelanosis) is common in cultured flatfishes, and is economically important. To understand the mechanism of blind-side hypermelanosis in flatfishes, we examined when the malpigmentation initially occurred, and studied how the symptoms proceeded during early development of the starry flounder, Platichthys stellatus. To assess quantitative pattern changes of blind-side skin, we observed morphological development of the whole body from 22 (total length [TL] 10.0 $\pm 0.2 \mathrm{~mm}$ and body weight [BW] $8.8 \pm 0.57 \mathrm{mg}$ ) to 110 days (TL $23.4 \pm 0.7 \mathrm{~mm}, \mathrm{BW}$ $193.6 \pm 23.3 \mathrm{mg}$ ) after hatching $(\mathrm{DAH})$, and also examined the malpigmented area rate of blind-side skin and the malpigmented fish ratios. The experimental animals were reared in fiberglass-reinforced plastic (FRP) tanks in water at a temperature of $18.9 \pm 1.9^{\circ} \mathrm{C}$ and salinity of $32.6 \pm 0.6$ psu and were fed with rotifer and Artemia nauplii from 22 to $48 \mathrm{DAH}$, and with A. nauplii and commercial feed from 49 to 110 DAH. As results, the first staining patch seen by the naked eye was observed around the area between the anus and pelvic fin or caudal edge of the trunk at $80 \mathrm{DAH}$ (TL 20.6 $\pm 0.5 \mathrm{~mm}$, BW $112.5 \pm 8.8 \mathrm{mg}$ ). The pigmented area and the pigmented fish ratios were significantly increased from 80 to $110 \mathrm{DAH}$. These results indicated that malpigmentation on the blind side of starry flounder was initially observed at about $2 \mathrm{~cm}$ in length and $100 \mathrm{mg}$ in weight, and the pigmented domain on the blind-side skin was continually broadened by the differentiation of pigmented cells (melanophores and xanthophores) with growth.
\end{abstract}

Key words : Blind side, Pigment, Early development, Hypermelanosis, Starry flounder

\section{INTRODUCTION}

The starry flounder, Platichthys stellatus, is a marine demersal heterosomatic fish (Pleuronectiformes) with both eyes located on the same side of the body (Byun et al., 2007; Ivankova \& Ivankov, 2006; Kang et al., 2012). The fish is bilaterally symmetrical after hatching, but becomes laterally asymmetrical after metamorphosis. During metamorphosis, the right (or left) eye migrates to the left (or right) side and occupies a position beside the left eye. The skin is asymmetrically pigmented on the ocular side (Byun et al., 2007). From hatching to metamorphosis, this fish has symmetrical body skin in which larval-type melanophores are evenly distributed. However, at the peak of metamorphosis, small adult-type melanophores, xanthophores, and iridophores are rapidly formed on only the ocular side. After metamorphosis, the ocular-side skin shows a distinct pigmentation pattern, but the blind-side skin shows no

\footnotetext{
Manuscript received 25 March 2014, Received in revised form 10 April 2014, Accepted 18 April 2014

$\dagger$ Corresponding Author : Duk-Young Kang, West Sea Fisheries Research Institute, NFRDI, 14 Sunyeo bawiro, Eulwang-dong, Joung-gu, Incheon 400420, South Korea. Tel.: +82-32-745-0711, E-mail: dykang69@gmail.com

This is an Open Access article distributed under the terms of the Creative Commons Attribution Non-Commercial License (http:// creativecommons.org/licenses/by-nc/3.0) which permits unrestricted non-commercial use, distribution, and reproduction in any medium, provided the original work is properly cited.
} 
pigment pattern (Byun et al., 2007). However, the blindskin malpigmentation of flatfish that accompanies mass production in hatcheries is a major problem (Fig. 1). As summarized by VenizelosBenetti (1999) and BolkerHill (2000), such malpigmentation has occasionally been observed in other wild-caught flatfishes, but is extremely rare in wild populations. The strong commercial value of starry flounder has made it a promising species for aquaculture and resource enhancement in South Korea; indeed, considerable mass aquaculture production is currently underway. However, the symptom is abnormally common in hatchery flatfishes, with up to $95 \%$ of hatchery-reared populations showing black areas on the blind side (Kang et al., 2011). In fact, malpigmentation is often used to distinguish cultured

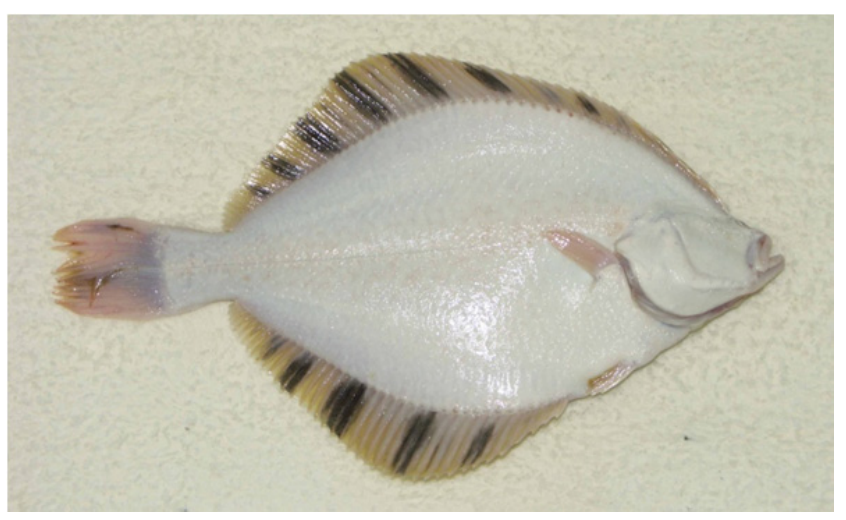

Wild type (normal blind side)

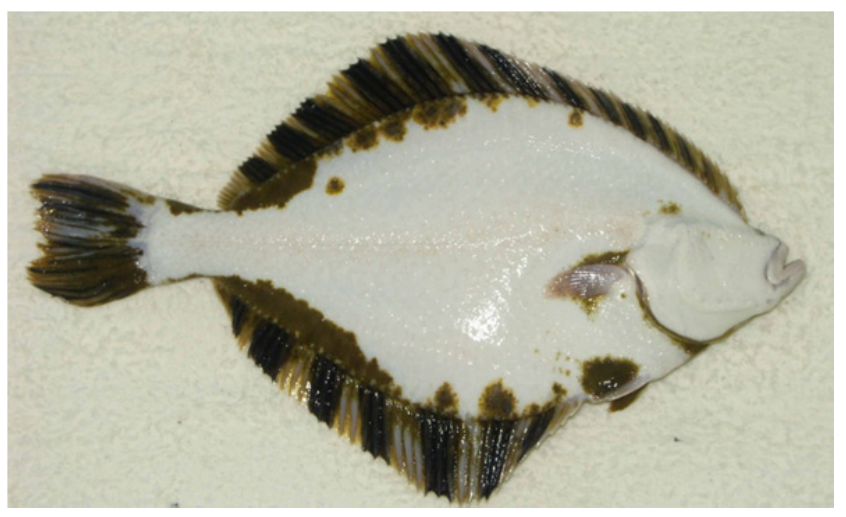

Cultured type (hypermelano blind side)

Fig. 1. Features of the blind side of wild and cultured starry flounders. from wild fish. Especially, this malpigmentation is considered an important problem with regard to resource conservation, marketing, and circulation of fishery products and the culture industry. In wild ecosystems, when hypermelanic flounders are released to enhance coastal resources, they could distort the natural inherited characteristics of starry flounder living in the wild. In addition, the malpigmentation is economically important in the fisheries industry. As malpigmented cultured flounders are sold at a lower price than ordinary flounders, blind-side malpigmentation is a common concern in culturing the fish due to customer preference.

Although many researchers have suggested that the cause of blind-side malpigmentation is the background color of the tank (Amiya et al., 2005; Stickney \& White, 1975), the brightness of light in the culture environment (Denson \& Smith, 1997; Iwata \& Kikuchi, 1998), diet (Hamre et al., 2005; Takeuchi et al., 1995), and bottom substratum and type of tank (Iwata \& Kikuchi, 1998; Kang \& Kim, 2012), the precise reason has not been clarified. In addition, we do not have sufficient knowledge regarding the mechanism underlying the appearance of malpigmentation. Therefore, methods of preventing or diminishing blind-side hypermelanosis in starry flounder artificially cultured at high densities are required. We are attempting to develop technical solutions based on an overall understanding of developmental malpigmentation on the blind side in flounder, but lack basic knowledge of the symptoms as they appear during mass production aquaculture. Before techniques to control undesirable pigmentation in fish raised in large-scale facilities can be developed, it is first necessary to determine when blind side hypermelanosis in starry flounder manifests during mass production aquaculture, elucidate the morphological and quantitative processes involved in this malpigmentation, and deduce its causes and mechanisms. To understanding the developmental properties of blind-side hypermelanosis, we analyzed the 
Morphological Analysis of Blind-Side Hypermelanosis of the Starry Flounder, Platichthys stellatus during Early Development

asymmetrical differentiation process of chromatophores during early development of starry flounder, and examined subsequent morphological pattern changes after metamorphosis.

\section{MATERIALS AND METHODS}

\section{Experimental animals and rearing performance}

In this study, we examined the pigmentation expression pattern on the blind side of starry flounder using the larvae from 22 days after hatching [DAH] (total length [TL]= $10.04 \pm 0.21 \mathrm{~mm}$, body weight $[\mathrm{BW}]=8.8 \pm 0.5 \mathrm{mg}]$. Observations were made during the 88 -day period from 22 to 110 DAH. Larvae were reared under natural photoperiod in tanks with water at a temperature of $15.6 \sim 23.3{ }^{\circ} \mathrm{C}$ and salinity of 31.1 33.6 psu (Fig. 2). As food, the fry at 22 48
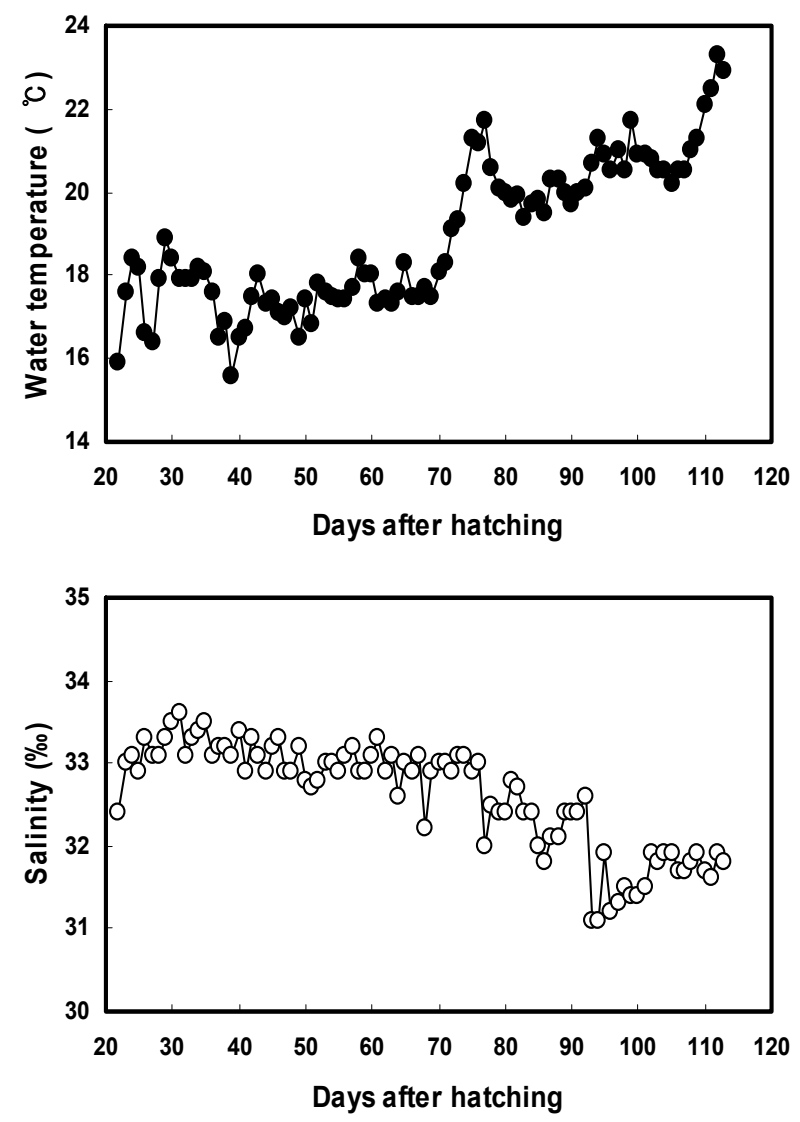

Fig. 2. Changes of water temperature and salinity during rearing experiment period.
DAH were supplied rotifers and Artemia nauplii, while Artemia nauplii and commercial pellets were provided at 49 100 DAH.

\section{Sampling and measurement}

Thirty flounders ( $n=30$ animals per sample point) were collected from each tank using a net at an interval of 7 or 10 days. The sampled fish were fixed in $10 \%$ neutralized formalin immediately after sampling. The fish were not fed for $24 \mathrm{~h}$ prior to sampling, and were anesthetized with 2phenoxyethanol (1/1,000 dilution, $0.3 \sim 0.4 \mathrm{mg} / \mathrm{L})$ and rinsed with distilled water to remove salt. The TL and BW of each animal were measured at an interval of 7 or 10 days. The total body surface area covering the bottom of the aquarium was also calculated and converted into PCA (percentage of covering area, \%). The blind sides of the sampled flounders were photographed with a digital camera (Dimage A2; Konica Minolta, Tokyo, Japan). The ratio of pigmented area of blind side (pigmented area of blind side/total area of blind side $\times 100 \%$ ) was analyzed with a microimaging analysis system (Qwin; Leica, Wetzlar, Germany) using the photographs. Individuals with a pigmented area of more than $1 \%$ on the blind side were considered ambicolored. The numbers of ambicolored individuals in each group were counted, and the ambicolored fish ratio (no. ambicolored fish/no. total fish $\times$ $100 \%$ ) was calculated at 7 - or 10-day intervals.

\section{Statistical analyses}

Statistical analyses were performed to determine the significance of differences in mean values between the groups in each experiment. The pigmented area ratio and the ambicolored fish ratio were compared using the means of the 30 pooled individuals $(n=30)$. Student's $t$ test or one-way ANOVA for parametric data $(n>30)$, and the Kruskal-Wallis test or Mann-Whitney U-test for nonparametric data $(n<30)$ were applied using the statistics 
software SPSS 7.0 (Korean version 7.50; SPSS Inc., Chicago, IL) with a $95 \%$ confidence level to compare differences in the data.

\section{RESULTS}

\section{Morphological expression of body color on the} blind side

At $24 \mathrm{DAH}$, before the body had transformed, the right (or left) eye of the flounder began to migrate toward the left (or right) side; in most fish, the migrated eye moved as far as the dorsal trunk ridge. Notochord flexion began, and the body started to flatten laterally. The body remained transparent on both sides. Many large (larval-type) melanophores, xanthophores, and iridophores were evenly distributed in the skin on both sides (Fig. 4). The larvae were 10.0 0.2 $\mathrm{mm}$ in length and weighed $8.8 \pm 0.5 \mathrm{mg}$ at this stage (Fig. 3).

The peak of metamorphosis, when migration of the eye was complete, occurred at $29 \mathrm{DAH}$. The lateral line was faintly distinguishable, and the fin ray and pectoral fins were clearly visible. Larval-type chromatophores were still observed on both sides. The ocular-side skin was pigmented by chromatophores, xanthophores, and iridophores, but pigment cells were diminished on the blind-side skin, which was still translucent (Fig. 4). At this stage, the larvae were $11.2 \pm 0.3 \mathrm{~mm}$ in length and weighed $16.0 \pm 1.1 \mathrm{mg}$ (Fig. 3).

At $36 \mathrm{DAH}$, the opposite side eye and intestines were visible through the transparent blind side. A pair of pectoral fins could be seen, and the number of larval chromatophores was decreased. The primitive pigmented spots composed of adult-type melanophores were slightly visible around the anus on the blind side by microscopic observation. However, the pigmented spot composed of adult-type melanophores on the blind side was not yet visible to the naked eye. Some of the flounders completed metamorphosis, and the first novel feature appeared (Fig. 4). At this stage, the fish were $13.7 \pm 0.5 \mathrm{~mm}$ in length and weighed $25.0 \pm 2.4 \mathrm{mg}$ (Fig. 3). At $43 \mathrm{DAH}$, the flounders


Fig. 3. Growth of juvenile starry flounder produced in artificial facility for 94 days after 22 DAH.

were still undergoing metamorphosis, and some fish had settled on the bottom of the tank. The body became weakly transparent (Fig. 4). At this stage, the fish were 15.9 \pm 0.4 $\mathrm{mm}$ in length and weighed $40.8 \pm 2.7 \mathrm{mg}$ (Fig. 3).

At $50 \mathrm{DAH}$, the lateral line was clearly distinguishable. Most of the flounders were completely at the juvenile stage of development. The number of larval-type melanophores on the blind side decreased. Adult-type melanophores were more numerous around the trunk between the pelvic fin and anus than in the previous stage. The first pigmented large spot (patch) was first observed by the naked eye around the trunk between the pelvic fin and anus in some of the flounders. However, the pigmented patch composed of three adult-type chromatophores on the blind side was not present elsewhere (Fig. 4). At this stage, the juveniles were $17.4 \pm 0.4 \mathrm{~mm}$ in length and weighed $53.6 \pm 3.5 \mathrm{mg}$ (Fig. 3).

At 57 and $64 \mathrm{DAH}$, the body was weakly transparent 
and the blind side became white in color. The pigmented patch could be seen by the naked eye around the trunk between the pelvic fin and anus in most of the flounders. The blind-side epidermis was a distinctive white color and was markedly less transparent, with the intestines no longer visible to the naked eye. Larval-type melanophores were still present in the blind-side dermis (Fig. 4). At this stage, the juveniles were $18.0 \sim 18.6 \mathrm{~mm}$ in length and weighed 55.4 67.9 mg (Fig. 3).

At $80 \mathrm{DAH}$, slight pigmentation of adult type was observed for the first time during development around the caudal peduncle on the blind side. In some fish, additional pigmented patches were first observed near the rear trunk beside the dorsal fins on the blind side. The pelvic fin was obviously pigmented. However, larval-type melanophores remained evenly distributed on the blind side (Fig. 4). At

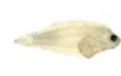

$22 \mathrm{DAH}$
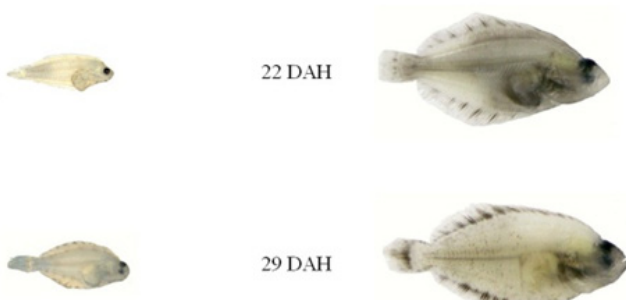

$29 \mathrm{DAH}$



$71 \mathrm{DAH}$

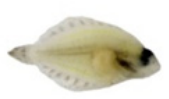

$36 \mathrm{DAH}$
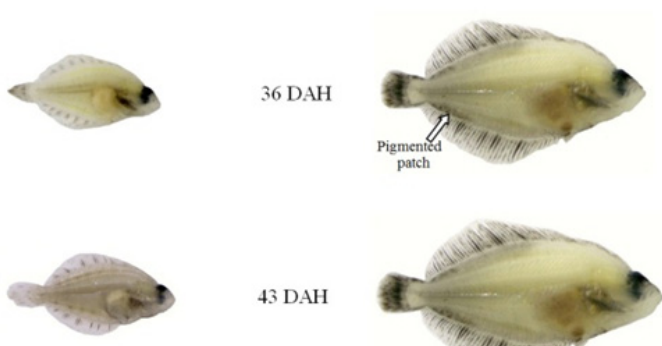

$43 \mathrm{DAH}$


$50 \mathrm{DAH}$

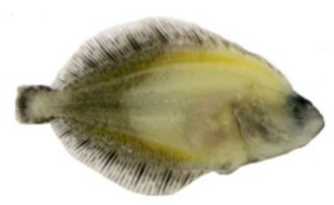

$110 \mathrm{DAH}$

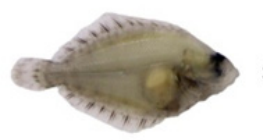

$57 \mathrm{DAH}$

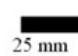

$64 \mathrm{DAH}$ $80 \mathrm{DAH}$

Fig. 4. Changes of the blind side of starry flounder during early development (DAH: day after hatching). this stage, the juveniles were $20.6 \pm 0.5 \mathrm{~mm}$ in length and weighed $112.5 \pm 8.8 \mathrm{mg}$ (Fig. 3).

From 92 110 DAH, the overall body shape resembled that of fish from the previous developmental stage, but a new feature appeared. Black pigmented patches composed of three adult-type chromatophores were more evident and were widespread around the trunk next to the rear dorsal fins on the blind side. Black spots composed of adult-type melanophores appeared around the pectoral fin and front trunk beside the dorsal fins, and on the eye vestiges on the blind side (Fig. 4). The spotted area on the blind side grew larger and darker. The mean TL increased from $20.8 \pm 0.5$ to $23.40 \pm 0.7 \mathrm{~mm}$, while the BW increased from $123.5 \pm$ 10.8 to $193.6 \pm 23.3 \mathrm{mg}$ (Fig. 3).

\section{Quantitative changes in the pattern of blind-side pigmentation}

Figures 5 and 6 show the quantitative changes in pigmentation pattern on the blind side from 24 to $110 \mathrm{DAH}$. From 20 to $70 \mathrm{DAH}$, no pigmented black spots composed of adult-type melanophores were found on the blind side. The primitive spot could first be seen by the naked eye on the rear trunk beside the dorsal fins at 80 DAH (Figs. 4 and 5). At $80 \mathrm{DAH}$, the percentage of staining area was extremely low $(2.8 \% \pm 1.4 \%)$, but the percentage of malpigmented



Fig. 5. Ratio (\%) of pigmented area in blind side of juvenile starry flounder produced in artificial facility for 94 days after 22 DAH. 


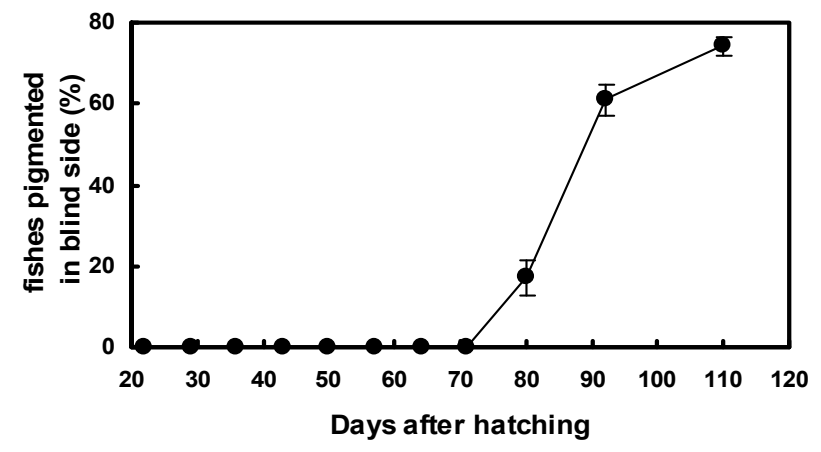

Fig. 6. Frequency ratio (\%) of fishes pigmented in the blind side among juvenile starry flounder produced in artificial facility for 94 days after 22 DAH.

fish was significantly high (17.1\% $\pm 4.2 \%)$ (Figs. 5 and 6). Up to $110 \mathrm{DAH}$, the staining area ratio increased markedly with growth to $10.6 \% \pm 3.0 \%$. The percentage of fish showing blind-side pigmentation increased markedly to $74.2 \% \pm 2.2 \%$ at $110 \mathrm{DAH}$ (Figs. 5 and 6).

\section{DISCUSSION}

Fish show two types of skin color change. The first is physiological color change (e.g., camouflage) in which fish match their color and skin pattern to those of the surrounding environment, while the second is irreversible skin color change due to the differentiation and development of chromatophores with growth. The former is a physiological color change, involving reversible movement of pigment in chromatophores to rapidly and transiently match skin pattern and colors to the surroundings (Ellis et al., 1997; Ramachandran et al., 1996) while the latter is a morphological change involving irreversible differentiation and development of chromatophores causing a quantitative increase in pigment. The hypermelanosis of blind-side skin of starry flounder observed in the present study is an example of the latter type of color change.

The ordinary starry flounder has numerous chromatoblasts just before metamorphosis. The chromatoblasts either differentiate into pigment cells or remain as stem cells, and are evenly distributed on the left and right epidermal sides. As the eye gradually migrates to one side during metamorphosis, the stem cells in the skin on the ocular side differentiate into three adult-type pigment cells (melanophores, iridophores, and xanthophores). However, the chromatoblasts on the non-ocular side gradually shrink and collapse during metamorphosis, and some later differentiate into iridophores. The result of these processes is that the starry flounder is asymmetrically colored after metamorphosis. The ocular side is variously colored. The non-ocular (blind) side is white. These observations confirmed earlier findings in other flatfishes reported by Minami (1982), Seikai (1992), and MatsumotoSeikai (1992). However, in our study, hypermelanic flounders showed abnormal differentiation of the chromatophores in a limited area of blind-side skin after metamorphosis, and most flounders exhibited malpigmentation on the blind side. Similar to the ocularside skin, a few pigment patches comprised of small adulttype chromatophores were observed near the dorsal fins on the blind side, indicating that these patches are not made by transient movement of pigment in chromatophores, but were formed irreversibly by differentiation of chromatophores. Such aberrant morphology has been demonstrated previously in many other Pleuronectiformes: olive flounder (Haga et al., 2005; Tomiyama et al., 2008); stone flounder, Kareius bicoloratus (Matsumoto \& Seikai, 1992); halibut, Hippoglossus hippoglossus (Ottesen \& Strand, 1996); barfin flounder, Verasper moseri (Yamanome et al., 2005); and yellowtail flounder, Limanda ferruginea (Purchase et al., 2002).

In addition, our quantitative investigation indicated that the abnormal pigmentation on the blind side showed consistent and irreversible developmental patterns. The proliferation of pigment cells in the blind-side skin was accelerated over time, and the size and number of pigmented patches increased with growth. The first pigment patch of the blind side visible to the naked eye appeared at 
$80 \mathrm{DAH}$. At this time, two to three pigmented patches were observed on the blind side. The average pigmented area ratio was $2 \sim 3 \%$, and the ratio of hypermelanic fish in the community reached $\sim 17 \%$. Up to $110 \mathrm{DAH}$, the staining area ratio increased markedly with growth to $10.6 \pm 3.0 \%$. The percentage of fish showing blind-side pigmentation increased markedly to $74.2 \pm 2.2 \%$.

Similar to other heterosomatic fishes (Amiya et al., 2005; Denson \& Smith, 1997; Diaz De Astarloa, 1995; Matsumoto \& Seikai, 1992), the blind-side malpigmentation of the starry flounder that appears at a very low ratio in wild populations was frequently observed in juvenile starry flounders reared in artificial facilities with a flat bottom and dark background. However, it is not yet clear why abnormal blind-side pigmentation occurs in flounders artificially cultured in high-density facilities. Several possible physical and ethological factors have been suggested to explain pigment anomalies in hatchery-reared Pleuronectiformes, including stress factors, light (Itoh et al., 2012; Iwata \& Kikuchi, 1998; Matsumoto \& Seikai, 1992), density (Takahashi, 1994), tank color (Yamanome et al., 2007; Yamanome et al., 2005), and bottom substratum (Estevez et al., 2001; Iwata \& Kikuchi, 1998; Kang \& Kim, 2012; Ottesen \& Strand, 1996). As hypermelanosis on the blind side of Pleuronectiformes occurs occasionally in wild flounders (Diaz De Astarloa, 1995; 1998; Stickney \& White, 1975), the symptom in flounders is likely to have a strong genetic component. Abnormal differentiation of adult-type melanophores on the blind side in flounders is evidently multifactorial, and both rearing stress and morphological evolution should be taken into consideration. Mass production facilities lack bottom shelters (e.g., mud, sand, or gravel), and flounders in these facilities are vulnerable to cannibalism. They compete for food with other flounders being reared in the same tank. These environmental stressors may select for adaptive camouflage on the blind side as well as on the ocular side. If such selection occurs and the appropriate conditions hold, chromatophores on the blind side degenerated (or atrophied) through evolution would re-differentiate.

In conclusion, primitive pigmentation on the blind side visible to the naked eye first appears in the trunk region around the dorsal fins and caudal peduncle at $80 \mathrm{DAH}$. Abnormal coloration resulting from differentiation of pigment cells on the blind side after metamorphosis extends to the entire blind side as growth proceeds. However, the molecular biochemistry from which abnormal pigmentation arises is not yet known. Future studies of the molecular endocrinological mechanism underlying the abnormal pigmentation in cultured olive flounder are required to clarify the developmental aspects of abnormal pigmentation indicated in the present study.

\section{ACKNOWLEDGMENTS}

This work was funded by a research grant (RP-2014-AQ051) from the National Fisheries Research and Development Institute (NFRDI), Republic of Korea.

\section{REFERENCES}

Amiya N, Amano M, Takahashi A, Yamanome T, Kawauchi H, Yamamori K (2005) Effects of tank color on melanin-concentrating hormone levels in the brain, pituitary gland, and plasma of the barfin flounder as revealed by a newly developed time-resolved fluoroimmunoassay. Gen Comp Endocr 143:251-256.

Bolker JA, Hill CR (2000) Pigmentation development in hatchery-reared flatfishes. J Fish Biol 56:1029-1052.

Byun S-G, Lee B-I, Lee J-H, Ku H-D, Park S-U, Yun S-M, Hwang S-Y, Kim Y-C, Han H-G (2007) Egg development and morphological change of larvae and juveniles of the starry flounder, Platichthys stellatus. Korean J Ichthyol 19:350-359.

Denson MR, Smith TIJ (1997) Diet and light intensity effects on survival, growth and pigmentation of Southern 
flounder Paralichthys lethostigma. J World Aquacult Soc 28:366-373.

Diaz de Astarloa JM (1995) Ambicoloration in two flounders, Paralichthys patagonicus and Xystreuris rasile. J Fish Biol 47:168-170.

Diaz de Astarloa JM (1998) An ambicolorate flounder, Paralichthys isosceles (Pleuronectiformes: Paralichthyidae), collected off Peninsula Valdes (Argentina). Cybium 22:187-191.

Ellis T, Howell BR, Hughes RN (1997) The cryptic responses of hatchery-reared sole to a natural sand substratum. J Fish Biol 51:389-401.

Estevez A, Kaneko T, Seikai T, Dores RM, Tagawa M, Tanaka M (2001) Ontogeny of ACTH and MSH cells in Japanese flounder (Paralichthys olivaceus) in relation to albinism. Aquaculture 202:131-143.

Haga Y, Nataami K, Takeuchi T (2005) Process of true ambicoloration in larval and juvenile Japanese flounder Paralichthys olivaceus: An ultrastructural study. Nippon Suisan Gakk 71:782-790.

Hamre K, Moren M, Solbakken J, Opstad I, Pittman K (2005) The impact of nutrition on metamorphosis in Atlantic halibut (Hippoglossus hippoglossus L.). Aquaculture 250:555-565.

Itoh K, Washio Y, Fujinami Y, Shimizu D, Uji S, Yokoi H, Suzuki T (2012) Continuous illumination through larval development suppresses dopamine synthesis in the suprachiasmatic nucleus, causing activation of $\alpha-\mathrm{MSH}$ synthesis in the pituitary and abnormal metamorphic skin pigmentation in flounder. Gen Comp Endocr 176:215-221.

Ivankova ZG, Ivankov VN (2006) Specific features of the external morphology of starry flounder Platichthys stellatus at atavism in the body color. J Ichthyol 46:436-440.

Iwata N, Kikuchi K (1998) Effects of sandy substrate and light on hypermelanosis of the blind side in cultured
Japanese flounder Paralichthys olivaceus. Environ Biol Fishes 52:291-297.

Kang DY, Kim HC (2012) Relevance of environmental factors and physiological pigment hormones to blindside hypermelanosis in the cultured flounder, Paralichthys olivaceus. Aquaculture 356-357:14-21.

Kang DY, Kim HC, Chang YJ (2011) Effects of stocking density on the blind-side hypermelanosis of cultured olive flounder Paralichthys olivaceus. Fisheries and Aquatic Science 14:123-129.

Kang DY, Lee JH, Kim WJ, Kim HC (2012) Morphological specificity in cultured starry flounder Platichthys stellatus reared in artificial facility. Fish Aqua Sci 15:117-123.

Matsumoto J, Seikai T (1992) Asymmetric pigmentation and pigment disorders in pleuronectiformes (flounders). Pigment cell research / sponsored by the European Society for Pigment Cell Research and the International Pigment Cell Society Suppl 2:275-282.

Minami T (1982) The early life history of a flounder Paralichthys olivaceus. Nippon Suisan Gakk 48:15811588.

Ottesen OH, Strand HK (1996) Growth, development, and skin abnormalities of halibut (Hippoglossus hippoglossus L.) juveniles kept on different bottom substrates. Aquaculture 146:17-25.

Purchase CF, Boyce DL, Brown JA (2002) Occurrence of hypomelanization in cultured yellowtail flounder Limanda ferruginea. Aquac Res 33:1191-1193.

Ramachandran VS, Tyler CW, Gregory RL, RogersRamachandran D, Duensing S, Pillsbury C, Ramachandran C (1996) Rapid adaptive camouflage in tropical flounders. Nature 379:815-818.

Seikai T (1992) Process of pigment cell differentiation in skin on the left and right side of the Japanese flounder, Paralichthys olivaceus, during metamorphosis. Jpn J Ichthyol 29:85-92. 
Morphological Analysis of Blind-Side Hypermelanosis of the Starry Flounder, Platichthys stellatus during Early Development

Stickney RR, White DB (1975) Ambicoloration in tank cultured flounder, Paralichthys dentatus. Trans Am Fish Soc 104:158-160.

Takahashi Y (1994) Influence of stocking density and food at late phase of larval period on hypermelanosis on the blind body side in juvenile Japanese flounder. Nippon Suisan Gakk 60:593-598.

Takeuchi T, Dedi J, Ebisawa C, Watanabe T, Seikai T, Hosoya K, Nakazoe J (1995) The effect of betacarotene and vitamin A enriched Artemia nauplii on the malformation and color abnormality of larval Japanese flounder. Fish Sci 61:141-148.

Tomiyama T, Mizuno T, Watanabe M, Fujita T, Kawata G
(2008) Patterns and frequency of hypermelanosis on the blind side in wild Japanese flounder. Nippon Suisan Gakk 74:171-176.

Venizelos A, Benetti DD (1999) Pigment abnormalities in flatfish. Aquaculture 176:181-188.

Yamanome T, Amano M, Amiya N, Takahashi A (2007) Hypermelanosis on the blind side of Japanese flounder Paralichthys olivaceus is diminished by rearing in a white tank: Short paper. Fish Sci 73:466-468.

Yamanome T, Amano M, Takahashi A (2005) White background reduces the occurrence of staining, activates melanin-concentrating hormone and promotes somatic growth in barfin flounder. Aquaculture 244:323-329. 